Revista NEP - Núcleo de Estudos Paranaenses, Curitiba, v.5, n.1, jun. 2019

Dossiê Partidos Políticos e Conexões Familiares

ISSN: 2447-5548

\title{
O GOLPE DE 2016: O PODER DAS INSTITUIÇÕES DO ESTADO NO BRASIL E AS ELEIÇÕES DE 2018
}

\author{
Maylson Calixto Buba ${ }^{1}$
}

RITSER, Claudio Rossano. O golpe de 2016: o poder das instituições do Estado no Brasil e as eleições de 2018. Rio de Janeiro: Multifoco, 2018. 480 p.

Claudio Rossano Ritser é autor dos livros Política sem ilusão: das alianças nos governos Lula e Dilma à crise política e impeachment (2016), 2016: golpe de Estado e a volta do neoliberalismo (2018) e O Golpe de 2016: O poder das instituições do Estado no Brasil e as eleições de 2018, os quais constituem a "Trilogia do Golpe". No posfácio do último livro, ele explica que vem de uma família tradicional conservadora sem ligações com a atuação política. Nos anos 1990, Ritser batiza-se na igreja evangélica e permanece nela por volta de 6 anos. No momento em que requer a filiação ao Partido dos Trabalhadores, em 2005, descobre que estava filiado ao Partido Social Cristão sem ter solicitado. Apenas em 2008, após cancelar o registro no PSC, consegue a aprovação de filiação no PT. O autor iniciou os cursos de administração, ciências sociais e de ciência política, porém, por diversos motivos não os concluiu. Ele destaca que suas obras trazem a visão de quem está fora da academia. No entanto, embasa seu pensamento em produções acadêmicas, além de utilizar textos publicados na imprensa. Ele demonstra em diversas passagens ter posições divergentes a cientistas políticos, especialmente quando coloca em análise a teoria em face da realidade política.

O livro O Golpe de 2016: O poder das instituições do Estado no Brasil e as eleições de 2018 apresenta a análise do tema dividido em quatro partes: a primeira dedica-se à direita $\mathrm{e}$ a constituição do Estado brasileiro e suas instituições; a segunda parte, e mais longa, trata da esquerda durante e após o golpe de Estado; as ações do governo golpista são analisadas no terceiro capítulo; e, por último, há uma breve complementação do segundo livro da Trilogia do Golpe, "2016: golpe de Estado e a volta do neoliberalismo".

É importante salientar que o autor parte de alguns pressupostos, os quais são fundamentais para entendermos a construção da argumentação ao longo da obra.

\footnotetext{
1 Graduado em Direito pela Universidade Federal do Paraná, discente do curso de Ciências Sociais da Universidade Federal do Paraná. Contato: calixtobuba@ufpr.br
} 
Revista NEP - Núcleo de Estudos Paranaenses, Curitiba, v.5, n.1, jun. 2019

As reflexões têm "caráter de classe" (p. 70), portanto, parte-se da ideia de que a sociedade está divida em classes. Existem os proprietários dos meios de produção de um lado e os trabalhadores que vendem a força de trabalho do outro. Assim sendo, evidencia que seus fundamentos teóricos estão alinhados com a posição marxista ou marxiana.

Ocorreu um golpe de Estado em 31 de agosto de 2016 e o autor ressaltará esta ideia do início ao fim da obra, destacando que não ocorreu, em reação ao golpe da direita, contragolpe por parte da esquerda. Afasta-se da tese de que houve legalidade constitucional no afastamento de Dilma Vana Rousseff da chefia do Poder Executivo do Estado brasileiro. Também se distancia da posição do cientista político André Singer, que sustenta que eleições com o expresidente Lula como candidato reparariam o tecido social afetado pelo impeachment de Dilma.

O terceiro e último pressuposto do pensamento de Claudio Rossano Ritser verificamos no seguinte excerto: "trabalho com o pressuposto de que tudo é política e todas as decisões, principalmente as relevantes socialmente, são fundamentalmente políticas"(RITSER, 2019, p. 109).

No primeiro capítulo do livro, o autor discorre acerca do viés político ideológico de direita do Estado brasileiro. Para tanto, faz um breve resgate histórico da formação do Estado de Direito Democrático e do Estado de Bem-Estar Social, a fim de ressaltar a presença do caráter de classe no modelo de Estado construído no contexto do capitalismo moderno.

Nesta sociedade capitalista, as classes sociais são divididas entre os proprietários dos meios de produção e os trabalhadores, estes últimos vendem suas forças de produção para os primeiros. Ao voltar os olhos para a sociedade brasileira, o autor destaca que ela tem como base fundamentos ideológicos de direita, ou seja, estão de acordo com os interesses da classe dos donos dos meios de produção. O autor argumenta que, desde 2003, com a eleição do candidato petista Luiz Inácio Lula da Silva à presidência do Brasil, a direita está na ofensiva contra a esquerda. Este tema retorna com maior ênfase no segundo capítulo do livro.

A ideia de que as instituições brasileiras estão abaladas é rejeitada, uma vez que a atuação do Parlamento e do Judiciário, por exemplo, estão de acordo com os interesses da classe dominante, ou seja, da direita. Esta direita não tem como objetivo a defesa de pautas civilizatórias, como a esquerda tem. 
Revista NEP - Núcleo de Estudos Paranaenses, Curitiba, v.5, n.1, jun. 2019

Após o golpe de Estado, o qual teve a finalidade de aplicar outra política, a de direita, não há democracia em pleno vigor no Brasil. Em 2013, com as manifestações de junho, e em 2015, início das discussões acerca do impeachment, as classes dominantes mostraram inconformidade com o governo da presidenta Dilma Rousseff.

$\mathrm{Na}$ obra, destaca-se a tese de que não precisamos da falsa democracia burguesa, precisamos do socialismo e da consciência de classe social para que mudanças sociais se efetivem na realidade. A direita, apesar da pluralidade de vertentes, possui consciência de classe fundada na proteção da propriedade privada e na defesa das normas definidas pelos donos dos meios de produção. Grande parte dos trabalhadores seguem o discurso da direita, em vez de construírem consciência de classe própria.

Finalizando as análises deste capítulo, o autor afirma que a esquerda retornará ao poder no médio ou longo prazo, uma vez que não houve de imediato o contragolpe. Portanto, a direita voltará ao poder para aplicar a pauta neoliberal, tendo o aval do Poder Legislativo, do Poder Judiciário, da mídia e de grande parte da sociedade civil.

Na segunda parte do livro, o autor propõe-se a tratar da esquerda. Vê-se uma análise crítica em relação às posições tomadas pela esquerda, especialmente o Partido dos Trabalhadores, durante e após o golpe de 2016.

A luta de classes fica cada vez mais evidente com as manifestações de junho de 2013, que são a radicalização da ofensiva da direita em ação desde 2003. Neste contexto, a esquerda parece perder a lucidez, o contato com a realidade social e política do momento em que passa o país. Exemplo disso nota-se em parte da esquerda não vislumbrar nas manifestações de 2013 um movimento de direita, o que é um equívoco analítico.

A realidade está na constatação de que a esquerda passa a ser situação se, e quando, houver anuência da direita, são necessárias alianças políticas com lideranças de centro para adquirir possibilidade de governabilidade. Destaque-se que a esquerda, representada por PT e o PC do B, é minoria no Brasil, inclusive o campo político da esquerda na sociedade brasileira corresponde a por volta de $20 \%$, situação que o autor ressalta em diversas partes da obra. Lula e Dilma não fizeram mudanças estruturais, a nossa sociedade é de direita, o eleitor tende a votar na direita. Veja-se o resultado dos pleitos de 2014, em que Aécio Neves quase obtém a vitória, e em 2018 na eleição de Jair Bolsonaro. Com o golpe, "a conjuntura política, ideológica e 
cultural, que é predominantemente de direita, continua com todo vigor em nossa sociedade" (RITSER, 2019, p. 280). É com esta realidade que a esquerda precisa lidar.

Partindo para uma crítica à esquerda legalista, Claudio Rossano Ritser (2019) frisa que o Direito segue os interesses da classe dominante, portanto, "a lei nunca foi e nunca será para todos e todas em uma sociedade de classes"(RITSER, 2019, p. 174). O vazamento ilegal de áudios de interceptação telefônica entre Lula e Dilma, o desinteresse do Ministério Público na ação de impugnação da chapa Dilma-Temer após o golpe de 2016, a posterior prisão de Lula e a impugnação da candidatura de Lula são exemplos da atuação política do Judiciário e do Ministério Público.

Apesar de todos estes fatos, o PT e a esquerda perderam-se no momento de estabelecer unidade no discurso. Houve a mudança de posição, de defesa à tese de que houve golpe para a de acreditar no funcionamento democrático das instituições. O discurso do golpe não se mantém, à esquerda falta força política e social para executar o contragolpe. Ao não retirar as candidaturas para o pleito de 2018 e a verificação de alianças entre PT e partidos que apoiaram o golpe, a esquerda, agora oposição, demonstrou abandono ao discurso de que houve um golpe de Estado. $\mathrm{O}$ autor critica tais atitudes da esquerda, porque, no fim, preferiu-se estratégias de curto prazo (eleições de 2018) a estratégias de médio e longo prazo, referentes ao retorno da esquerda ao poder após a consumação do golpe de Estado com a aplicação da política neoliberal da direita.

A mudança da conjuntura necessita da consciência de classe dos(as) trabalhadores(as), bem como da participação eleitoral com voto em quem tem compromisso de classe, do contrário, permanecerá o domínio dos detentores dos meios de produção disseminado pelas instituições brasileiras.

Esta parte da obra é a mais densa e, portanto, mais longa, com muitas informações sobre as movimentações políticas das lideranças de esquerda, além de expor posições de cientistas sociais acerca do cenário político, institucional e social do Brasil. Na continuação, o terceiro capítulo discorre sobre o Brasil que os governos Lula e Dilma construíram, apesar de não efetuarem alterações estruturais, e como o governo golpista de Michel Temer começa a destruir as mínimas conquistas sociais dos governos petistas.

A reforma da Previdência Social e trabalhista são o foco do governo golpista de Michel Temer, que, inclusive, demonstra ter pressa na aprovação de propostas legislativas, sob a 
justificativa de que o crescimento da economia depende destas alterações legais. O trabalhador, após o golpe, torna-se o alvo e assume posição de grande vulnerabilidade com estes ataques a direitos sociais mínimos, chamados, pelo autor, de "migalhas" concedidas pela classe dominante.

Nas gestões de Lula, tendo em vista a realidade brasileira, houve enormes avanços sociais. E o governo Dilma acertou na política macroeconômica. No entanto, ambos não abandonaram o neoliberalismo, pois a esquerda não tem forças para enfrentar os donos do capital. No momento em que Dilma começa a incomodar o mercado com política mais agressiva, vemos as jornadas de junho de 2013 abrirem um novo momento da ofensiva da direita. O cenário internacional adverso (crise financeira de 2008) e aos erros de condução econômica (desonerações tributárias e isenções encargos sociais, sem que ocorressem contrapartidas) são fatores a serem considerados na crise política do começo do segundo mandado de Dilma, que abriu caminhos para a direita unir forças em torno do objetivo do golpe de Estado.

Após os governos de Fernando Henrique Cardoso, os donos do capital se veem novamente representados na presidência da república por Michel Temer. De modo diverso, os governos Lula e Dilma tinham como objetivo beneficiar a maioria da população.

O autor destaca que, neste contexto de incertezas políticas, Temer indica seu ministro da justiça Alexandre de Moraes para a vaga de Teori Zavaski no Supremo Tribunal Federal. O objetivo desta jogada política foi o de segurar a articulação do golpe dentro do golpe que parte dos membros do PSDB defendiam. Ou seja, além de tirar Dilma da presidência, havia setores do PSDB articulando a queda de Temer também.

A esquerda sofre diversas derrotas, dentre elas podemos citar: o golpe de Estado contra Dilma, os retrocessos sociais do governo Temer, a aprovação da Proposta de Emenda Constitucional apelidada de PEC do teto dos gastos públicos e a reforma trabalhista. Isto tudo ocorre entre o golpe e o fim do governo Temer.

A estrutura da sociedade não se altera com o golpe, mantém-se os interesses da classe burguesa, mas os agentes políticos precisam se readequar ao momento de alteração de Presidentes da República. Tome-se como exemplo a atuação de Renan Calheiros (PMDB): $1^{\circ}$ ) aliado de Lula e Dilma; $2^{\circ}$ ) alia-se a Michel Temer; $3^{\circ}$ ) critica a gestão e a política de Temer. 
Para Ritser, fica evidente que as "instituições do Estado agem ou deixam de agir conforme os interesses de classe" (RITSER, 2019, p. 366).

A parte final do livro é um complemento ao livro do mesmo autor "2016: golpe de Estado e a volta do neoliberalismo". Ressalta-se a participação das instituições do Estado no golpe de 2016, além da influência dos meios de comunicação na obtenção de apoio da população.

Houve a ruptura da ordem democrática em 2016, situação difícil de analisar sem afastamento histórico, porém, o autor defende a ideia de que existem elementos da conjuntura política e social que são passíveis de análise sem tal afastamento.

A atuação do setor econômico é fundamental na análise da conjuntura atual do Brasil. Não foi apenas inabilidade política que tirou Dilma da presidência da República. A democracia burguesa segue os interesses da classe dominante, mesmo que para tanto seja necessário violar a Constituição da República, por meio de golpe de Estado.

Os textos apresentados na obra, em sua maioria, foram publicados em meio virtual como análises políticas dos acontecimentos, tendo como base a cobertura dos fatos mais relevantes durante e após o golpe de Estado. Por isso, nota-se em alguns momentos repetições de argumentos já expostos suficientemente. No final de cada capítulo, nos é apresentado um texto teórico fazendo conexão com os fatos. As posições tomadas pelo autor ao longo da obra têm teor crítico, não só em relação à direita, mas em relação à atuação da própria esquerda na atual conjuntura política.

Claudio Rossano Ritser faz questão de destacar na apresentação do livro e no posfácio que ele não parte de uma neutralidade acadêmica, pois atua politicamente na esquerda, é filiado ao PT. Apesar destas considerações, ele defende que é possível conciliar sua atuação política com a proposição de análises críticas da conjuntura política e social brasileira. Aliás, a maior parte do livro é dedicada à crítica às posições tomadas pela esquerda, revelando as incoerências discursivas e os erros estratégicos.

Esta obra é indicada tanto para quem tem interesse em conhecer melhor os eventos que culminaram no golpe de 2016 e no cenário político da eleição de 2018, quanto para quem acompanhou os eventos, pois fornece uma visão minuciosa dos acontecimentos políticos e nos 
Revista NEP - Núcleo de Estudos Paranaenses, Curitiba, v.5, n.1, jun. 2019

faz relembrar de fatos importantes que escapam à memória com o passar do tempo e com os novos acontecimentos na atual conjuntura de incertezas e retrocessos a cada dia que se passa.

Recebido em: 31 maio 2019.

Aceito em: 05 jun. 2019. 